\title{
A COMPARISON OF THREE TERMINAL SIRE BREEDS FOR CROSSBRED LAMB PRODUCTION
}

\section{GROWTH PERFORMANCE AND CARCASS CLASSIFICATION}

\author{
B. G. MERRELL ${ }^{1}$, G. M. WEBSTER ${ }^{2}$ and M. ELLIS ${ }^{2}$ \\ ${ }^{1}$ MAFF/ADAS, Redesdale EHF, Rochester, Otterburn, Newcastle upon Tyne NE19 ISB \\ ${ }^{2}$ Department of Agriculture, The University, Newcastle upon Tyne NE1 TRU
}

\section{INTRODUCTION}

$\mathbf{L}$ amb carcass quality is becoming more important as consumer demand for lean meat increases. As a result, financial premiums are now being paid for leaner carcasses of good conformation. The choice of terminal sire represents the most immediate option availabie to the producer to influence lamb growth performance and carcass quality.

Cameron and Drury (1985) combined the results of three major breed evaluations (Wolf, Smith and Sales, 1980; Croston, Guy, Jones and Kempster, 1983; Cameron and Drury, 1985), using the overlap in breeds between trials to produce data on 15 terminal sire breeds. Although these included a comparison of the Suffolk, Texel and Charollais breeds, they were not from the same trial or under similar management conditions. This paper reports on the evaluation of the crossbred progeny from Suffolk, Texel and Charollais rams reared under common management and from the same female population and thus provides a direct comparison between these three sire breeds. Data are presented on the first 2 years of a 3-year trial.

\section{MATERIAL AND METHODS}

The trial was started in 1986 using an upland flock of 348 regular-aged (1.5 to 5.5 years) Mule ewes (Bluefaced Leicester $\sigma^{\prime} \times$ either Scottish Blackface or Swaledale ). In the 1st year of the trial, ewes of both dam types were well represented with about two-thirds of Scottish Blackface origin and one-third Swaledale. In the 2nd year, the ewes were from Scottish Blackface dams only.

The ewes were mated to Suffolk, Texel and Charollais rams which were selected as being typical of those commercially available for each breed. Two sires of each breed produced progeny in 1987 and four per breed in 1988 , with different, unrelated rams being used in each year. Ewes were divided into balanced groups according to dam type, age, live weight and body condition and each group was randomly allocated to an individual ram for a 22-day mating period, beginning in early November each year. These groups comprised 58 ewes in the 1st year and 29 ewes in the 2nd year.

After the initial mating period, the test rams were removed and the groups combined, with commercial Suffolk rams being allowed to mate any ewes returning to oestrus. The management of the ewes, and subsequently the ewes with their lambs, was the same throughout, except for the initial division into mating groups. The flock was out-wintered and given baled silage with supplementary concentrate food introduced during the final 7 weeks of pregnancy.

Lambs were tagged at birth, and weighed at birth, 30, 86 and 119 mean days of age, and at slaughter. They were weaned when they were 119 days old (mean) and subsequently grazed silage aftermaths during which time they were dosed against intestinal parasites at 3-week intervals. The lambs were selected for slaughter at an equal estimated level of subcutaneous fat cover, equivalent to Meat and Livestock Commission (MLC) fat classes 2 and $3 \mathrm{~L}$. The level of fat cover was assessed by subjective handling of the loin area.

All lambs were slaughtered at a single commercial abattoir and MLC carcass classification information and carcass weight were recorded. In each year carcasses were selected on each of the four main slaughter dates for subsequent dissection. Details of the dissection procedure and the resulting analysis are described in the companion paper (Webster, Ellis and Merrell, 1990).

Only data from multiple-born, twin-reared lambs were analysed. Lambs which were born more than 140 days after the test rams had been removed were considered of uncertain pedigree and were not included in the analysis. Neither were those that had been cross-fostered. All data were subjected to analysis of variance using Genstat V (Payne, Lane, Ainsley, Bicknell, Digby, Harding, Leech, Simpson, Todd, Verrier, White, Gower, Tunnicliffe Wilson and Paterson, 1987) by breed, year, sire and sex with appropriate interactions. Fat class and conformation scores were transformed to integer values prior to analysis. 
TABLE 1

Daily live-weight gain of crossbred lambs $(g)$

$\begin{array}{llllr}\quad \text { No. of lambs } & 297 & 276 & 304 & \\ \text { Birth to } 30 \text { days } & 341 & 335 & 326 & 9 \cdot 5 \\ 30 \text { to } 86 \text { days } & 285^{\mathrm{a}} & 272^{\mathrm{b}} & 277^{\mathrm{ab}} & 5 \cdot 8 \\ 86 \text { to } 119 \text { days } & 169 & 161 & 166 & 23 \cdot 1 \\ \text { 119 days to slaughter } & 131^{\text {ab }} & 104^{\mathrm{a}} & 146^{\mathrm{b}} & 18 \cdot 2 \\ \text { Birth to weaning } & 279 & 269 & 270 & 5 \cdot 9 \\ \text { Birth to slaughter } & 262 & 250 & 249 & 9 \cdot 6\end{array}$

ab Means with different superscripts significantly different $(P<0.05)$.

TABLE 2

Slaughter traits of crossbred lambs

\begin{tabular}{|c|c|c|c|c|}
\hline & Suffolk & Texel & Charollais & s.e.d. $(15$ d.f. \\
\hline Slaughter age (days) & 143 & 144 & 149 & $6 \cdot 2$ \\
\hline Live weight at slaughter $(\mathrm{kg})$ & $41 \cdot 2^{\mathrm{a}}$ & $39 \cdot 7^{\mathrm{b}}$ & $41 \cdot 0^{\mathrm{a}}$ & 0.57 \\
\hline Carcass weight $(\mathrm{kg})$ & $18 \cdot 0$ & $17 \cdot 7$ & $18 \cdot 2$ & 0.43 \\
\hline Carcass-weight gain (g/day) & 112 & 110 & 108 & $4 \cdot 6$ \\
\hline Killing-out proportion $(\mathrm{g} / \mathrm{kg})$ & 437 & 446 & 443 & 5 \\
\hline Fat score $\dagger$ & $9 \cdot 91^{\mathrm{a}}$ & $9 \cdot 62^{\mathrm{a}}$ & $10 \cdot 42^{b}$ & 0.259 \\
\hline Conformation score & $2 \cdot 95^{\mathrm{a}}$ & $2 \cdot 71^{\mathrm{b}}$ & $2 \cdot 98^{\mathrm{a}}$ & $0 \cdot 086$ \\
\hline
\end{tabular}

\section{RESULTS}

There were significant differences between years and between sexes for most growth and carcass traits but since year $\times$ breed and sex $\times$ breed interactions were not significant, the data are presented by breed only.

At all ages after birth, Suffolk-cross lambs tended to be heavier than those of the other two breeds and at 30 days they were significantly heavier than Charollais crosses (Suffolk: 15.1, Texel: 14.8, Charollais: $14.5 \mathrm{~kg}$, s.e.d. $0 \cdot 28 ; P<0 \cdot 05$ ). Daily live-weight gains of the 877 lambs included in the analysis are shown in Table 1 from which it can be seen that Suffolk-cross lambs tended to grow fastest up to weaning. Thereafter, Charollais crosses had the highest mean growth rate and this was significantly better than that of the Texels $(P<0.05)$. Conversely, growth rate of Texel-cross lambs after weaning was poorer than that of the other two breeds. Overall, there were no significant differences between breeds in daily live-weight gains from birth to weaning or birth to slaughter (Table 1), although Suffolk-cross lambs tended to have higher growth rates than the other two crosses during these periods.

There were no significant breed differences in age at slaughter, although Suffolk-cross lambs were killed on average 6 days earlier than Charollais crosses but at a similar live weight (Table 2). Lambs sired by Texel rams were significantly lighter at slaughter $(P<0.05)$ and produced slightly smaller carcasses than those from the other two breeds.

Table 2 also shows that there were differences between breeds in the actual fat scores of the carcasses,

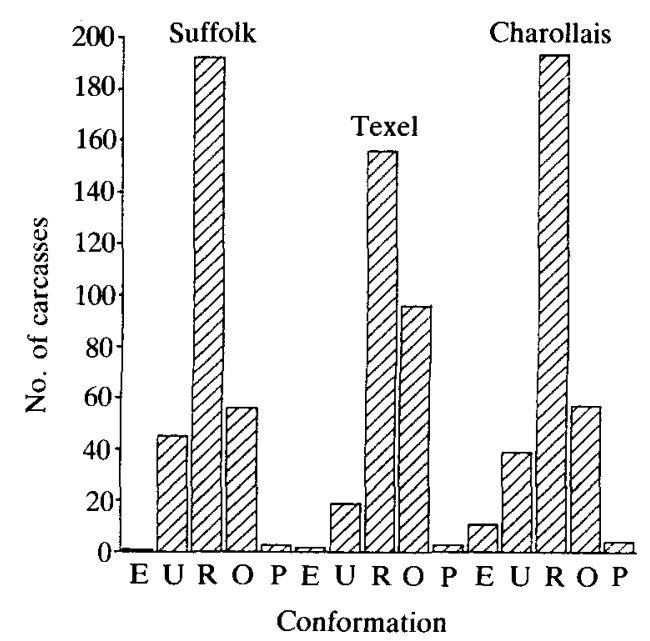

FIG. 1 Distribution of MLC conformation scores. 
TABLE 3

Daily live-weight gain and slaughter traits of crossbred lambs slaughtered at MLC fat classes 2 and $3 L$

\begin{tabular}{|c|c|c|c|c|}
\hline & Suffolk & Texel & Charollais & s.e.d. (15 d.f.) \\
\hline No, of lambs & 282 & 256 & 241 & \\
\hline \multicolumn{5}{|l|}{ Live-weight gain (g/day) } \\
\hline Birth to weaning & 281 & 269 & 272 & $6 \cdot 0$ \\
\hline Birth to slaughter & 266 & 252 & 254 & $7 \cdot 3$ \\
\hline \multicolumn{5}{|l|}{ Slaughter traits } \\
\hline Slaughter age (days) & 141 & 142 & 147 & $6 \cdot 4$ \\
\hline Live weight at slaughter $(\mathrm{kg})$ & $41 \cdot 1^{\mathrm{a}}$ & $39 \cdot 5^{\mathrm{b}}$ & $41 \cdot 0^{\mathrm{ab}}$ & 0.74 \\
\hline Carcass weight (kg) & $17 \cdot 9$ & $17 \cdot 5$ & $18 \cdot 1$ & 0.41 \\
\hline Fat score $\dagger$ & $9 \cdot 53$ & $9 \cdot 38$ & $9 \cdot 56$ & $0 \cdot 189$ \\
\hline Conformation score $\ddagger$ & $2 \cdot 93^{\mathrm{a}}$ & $2 \cdot 70^{\mathrm{b}}$ & $2 \cdot 98^{\mathrm{a}}$ & $0 \cdot 083$ \\
\hline
\end{tabular}

ab Means with different superscripts significantly different $(P<0.05)$.

$\dagger$ Estimated subcutaneous fat.

$\ddagger$ MLC conformation score $\mathbf{E}=5, \mathbf{P}=1$.

with Charollais crosses being significantly fatter than the Suffolks or Texels $(P<0.05)$. There was also a significant breed difference $(P<0.05)$ in mean conformation score, with Suffolk and Charollais crosses having superior scores to those from the Texel (Table 2). This was due to a difference $\left(\chi^{2}=37 \cdot 9,8\right.$ d.f.; $P<0.001)$ in the distribution of conformation scores between breeds as shown in Figure 1.

The initial experimental design provided for lambs to be slaughtered in MLC fat classes 2 and $3 \mathrm{~L}$ and $89 \%$ of the lambs conformed to this criterion. When the analysis was confined to lambs slaughtered in fat classes 2 and $3 \mathrm{~L}$ only, there was little change in the mean growth and carcass measurements (Table 3) and differences between breeds in carcass conformation remained significant $(P<0.05)$.

\section{DISCUSSION}

On upland farms the production of mid-season finished lambs requires a terminal sire breed which imparts to its crossbred progeny rapid growth and a good quality carcass without detrimental effects on lamb survival.

There were no differences in neonatal mortality between the breeds of lamb despite Charollais crosses having only sparse fleece cover at birth. However, Charollais-cross lambs tended to grow more slowly to 30 days of age when they were significantly lighter than the Suffolks. This may reflect a higher requirement for heat production in the Charollais lambs.

Differences in live-weight gain and carcass weight gain between Suffolk and Texel crosses were less than those reported by More O'Ferrall and Timon (1977) and Wolf et al. (1980) but similar to those reported by Kempster, Croston, Guy and Jones (1987). The slower growth rate, but leaner carcasses of the Texel compared with the Suffolk has led to the suggestion that Texel rams should be used to produce heavier carcasses at the same level of fat cover. However, in the present study there is no evidence to support this. When slaughtered at an equal level of fat cover, Texel-cross lambs were the same age as those of the Suffolk but were of significantly lighter slaughter weight and produced slightly lighter carcasses. The reverse result was reported by Wolf $e t a l$. (1980)

Charollais crosses took 6 days longer than Suffolk crosses to reach slaughter at equal fat score. Since the present pricing structure for sheep meat financially penalizes lambs which finish later than others in the summer, this may be sufficient to deter producers from using Charollais sires. With the abolition of the variable premium, age to slaughter will take on less significance and carcass quality will be more important in determining financial returns. This may enhance the appeal of the Charollais as a terminal sire breed.

In this study the conformation of Texel carcasses was inferior to those of the other two breeds. Wolf $e t$ al. (1980) found Texel carcasses to be superior to those of the Suffolk and Kempster et al. (1987) found no significant differences in carcass conformation between these two breeds. In the latter of these two trials, Texels of the French type were used which have not been selected for carcass conformation to the same degree as the Dutch Texels (Visscher and Bekedam, 1984). In the trial reported here, the Texel sires were predominantly of the Dutch type and would have been expected to impart good conformation to their progeny. However, lambs were generally slaughtered at lower levels of fat cover (mean estimated subcutaneous fat proportion $99.8 \mathrm{~g} / \mathrm{kg}$ ) than those reported by other authors and superior conformation of Texel crosses was not observed under such conditions. 
The results from the six rams evaluated so far of each sire breed showed Suffolk crosses to have higher growth rates than those of the other two breeds. Texel-sired lambs had poor growth rates post weaning and produced carcasses of poorer conformation than those sired by Suffolk or Charollais rams. At an equal level of estimated fat cover, Charollais crosses produced carcasses of slightly heavier weight and better conformation than Suffolk crosses but took longer to reach slaughter condition.

\section{ACKNOWLEDGEMENT}

The assistance of the Suffolk, Texel and Charollais breed societies with the selection and identification of suitable unrelated sires is gratefully acknowledged.

\section{REFERENCES}

Cameron, N. D. and Drury, D. J. 1985. Comparison of terminal sire breeds for growth and carcass traits in crossbred lambs. Animal Production 40: 315322.

Croston, D., Guy, D. R., Jones, D. W. and KempSter, A. J. 1983. A comparison of ten sire breeds for sheep production. 1. Growth performance and carcass classification. Animal Production 36: 504 (Abstr.).
Kempster, A. J., Croston, D., Guy, D. R. and Jones, D. W. 1987. Growth and carcass characteristics of crossbred lambs by ten sire breeds, compared at the same estimated carcass subcutaneous fat proportion. Animal Production 44: 83-98.

More O'Ferrall, G. J. and Timon, V. M. 1977. A comparison of eight sire breeds for lamb production. 1. Lamb growth and carcass measurements. Irish Journal of Agricultural Research 16: 267-275.

Payne, R. W., LAne, P. W., Ainsley, A.E., Bicknell, K. E., Digby, P. G. N., Harding, S. A., Leech, P. K., Simpson, H. R., Todd, A. D., Verrier, P. J., White, R. P., Gower, J. C., Tunnicliffe Wilson, G. and Paterson, L. J. 1987. Genstat $V$ Reference Manual. Oxford University Press, Oxford.

Visscher, A. H. and BEKEdAM, M. 1984. The development of the Texel breed in the Netherlands. Proceedings of the 35th Meeting of the European Association for Animal Production, The Hague, Vol. 2, paper 4.1 (Abstr.).

Webster, G. M., Ellis, M. and Merrell, B. G. 1990. A comparison of three terminal sire breeds for crossbred lamb production. 2. Carcass evaluation. In New Developments in Sheep Production (ed. C. F. R. Slade and T. L. J. Lawrence), Occasional Publication, British Society of Animal Production, No. 14, pp. 173-175.

Wolf, B. T., SMITH, C. and SAles, D. I. 1980. Growth and carcass composition in the crossbred progeny of six terminal sire breeds of sheep. Animal Production 31: 307-313. 